\title{
El Nacionalsocialismo de Heidegger o el abandono de las cosas mismas ${ }^{1}$
}

\author{
Felipe Johnson ${ }^{2}$
}

Recibido: 31 de agosto de 2015 / Aceptado: 17 de marzo de 2016

Resumen. Este artículo problematiza la relación de Heidegger con el Nacionalsocialismo para discutir cómo es que ella se gesta desde una ceguera en su propio pensar. Atendiendo a sus Cuadernos Negros, en especial al volumen referente a los años 30, se analizará la posición crítica de Heidegger a Ser y Tiempo y las nuevas tendencias en su pensar para entender el horizonte comprensivo en el que éste asume posturas políticas fácticas como rector de la Universidad de Freiburg. Así, se mostrará que tanto su planteamiento filosófico como sus posturas políticas obedecen a un único horizonte de problemáticas: el tiempo y su traducción histórico-política en tanto que destino. Desde esta primacía del tiempo, indagaremos cómo la filosofía heideggeriana es conducida a un descuido de lo inmediato. Así es como esta labilidad será comprendida como el motivo por el cual dicho pensamiento, en los Cuadernos Negros, se anula a sí mismo en cuanto filosofía.

Palabras clave: futuro; temporalidad; política; nacionalsocialismo; Heidegger.

\section{[en] Heidegger's Nacional Socialism or the abandonment of the things themselves}

\begin{abstract}
This paper problematizes Heidegger's relationship with National Socialism in order to discuss how it stems from certain blindness in his own thinking. By focusing on the Black Notebooks, especially the volume that corresponds to the 1930 s, we will analyze Heidegger's critical position on Being and Time and his new intellectual inclinations, so that the horizon of sense be clarified in which Heidegger takes over factual political positions as rector of the University of Freiburg. So, we attempt to point out that both his philosophical approach and his political stance obey to a single context of problematics: both time and its historical political translation as destiny. From this primacy of time, we will investigate how Heidegger's philosophy is led to a neglect of the immediate. Finally, this lability will be referred as the reason which explains that Heidegger's thought, in the Black Notebooks, invalidates itself as philosophy.
\end{abstract}

Keywords: future; temporality; politics; nacional socialism; Heidegger.

Sumario. 1. Las manos de Hitler y la ceguera en el pensar; 2. La decepción de Ser y Tiempo: el abandono del presente; 3. La primacía del futuro y la imposición de un "destino propio"; 4. La reformulación universal del presente: la educación nacionalsocialista; 5 . Auto-anulación del pensar: el llamado lábil a la auto-apropiación; 6. Referencias bibliográficas.

Cómo citar. Johnson, F. (2017): "El Nacionalsocialismo de Heidegger o el abandono de las cosas mismas", en Revista Anales del Seminario de Historia de la Filosofía 34 (1), 185-202.

1 Este trabajo se realizó en el marco del Proyecto DIUFRO: DI-14-0055: La presentación futura del Ahi: la fundación temporal del Existir en Heidegger, de la Universidad de La Frontera.

2 Universidad de La Frontera, Chile

felipe.johnson@ufrontera.cl 


\section{Las manos de Hitler y la ceguera en el pensar}

La publicación de los Cuadernos Negros, el año $2014^{3}$, viene a reanimar una discusión que no ha sido en absoluto desconocida para los lectores de Martin Heidegger: su relación con el Nacionalsocialismo ${ }^{4}$. Es cierto que el tema ha sido subrayado más de una vez, con más o menos bríos, en el afán de detectar en su obra tendencias totalitarias, antisemitas, o, en el caso contrario, de distinguir su pensar de eventuales ideologías que desmerezcan sus aportes a la discusión filosófica, de la cual el siglo XX puede considerarse deudor 5 . Ahora bien, a pesar de que el estudio de Heidegger sigue concentrándose en mayor medida en su filosofía, esto es, en la aclaración de su punto de partida fenomenológico-hermenéutico, en su confrontación con la tradición filosófica, con los Cuadernos Negros la discusión acerca de la adhesión política de Heidegger y la consecuente pregunta por la relación entre filosofía y política parecen volverse temas ineludibles entre quienes lo estudian.

Por lo pronto, no es secreto que Heidegger haya escuchado entusiasta los primeros discursos de Hitler. Conocida es la anécdota de Jaspers, quien en 1933 le comentaría a su entonces amigo: “¿Cómo puede gobernar Alemania un hombre tan poco formado como Hitler?", a lo cual Heidegger replicaría: "La formación es completamente indiferente, sólo mire usted sus magníficas manos" ". La expresión es referida también así: "Mire usted las manos de Hitler y verá inmediatamente lo extraordinario" ". Como sea, el relato de Jaspers no deja de plantear un problema efectivo que es aquel sobre el cual quisiéramos esbozar algunas reflexiones. $\mathrm{Y}$ es que el entusiasmo del Heidegger de la anécdota podría corresponder a cualquier ciudadano que identifique el liderazgo político con la elocuencia. Mas la dirección de un pueblo pareciera ir más allá del mero efecto que el orador provoca entre los oyentes. El guía de un gobierno requiere una sólida formación, y esto no sólo respecto de las herramientas para gestionar su poder, sino de aquella formación que le proporcionaría la prudencia como para discernir entre las mejores posibilidades en vistas al bienestar de quienes lidera.

Así, mientras que la anécdota se traduce en un diálogo entre quien sabe que la elección de tal líder influirá necesariamente tanto en la vida pública como individual, posición representada por Jaspers, la observación de Heidegger se deja entender como la expresión de un entusiasmo irresponsable, propio de cualquiera que sea

3 Cfr. Adrián, J. «Heidegger's Black Notebooks and the Question of Anti-Semitism». Gatherings: The Heidegger Circle Annual, 5, 2015. El autor describe en detalle la coordinación entre Heidegger y Vittorio Klostermann de los Cuadernos Negros, así como otros detalles pertinentes a su publicación.

4 Es sabido que la controversia comienza ya en 1945, con una entrevista a Karl Löwith en Le temps modern (cfr. Rockmore, T. On Heidegger's Nazism and Philosophy. Oxford: University of California Press, 1992). Luego continuará Víctor Farías con su libro Heidegger y el Nazismo (1987) y Hugo Ott con Martin Heidegger: en camino a su biografia (1988). Asimismo, Emmanuel Faye escribirá su Introducción del nacismo en la filosofía (2005) (cfr. Farías, V. «El ser y el crimen: los Cuadernos Negros de Martin Heidegger y la espiritualización de la inhumanidad». Stoa, 5, 10, 2014, pp. 105-113.). Para una réplica a las tesis de Farías, cfr. Aubenque, P. «Otra vez Heidegger y el Nazismo». Revista de Filosofia, I, 1987-88, pp. 157-169.

5 Collins refiere la gran cantidad de pensadores influenciados por Heidegger. Entre ellos cuentan Sartre, MerleauPonty, Lévinas, Derrida, Deleuze, Guattari, Foucault, Lacan (cfr. Collins, J. Heidegger y los nazis. Barcelona: Ed. Gedisa, 2004). Por otra parte, su pensar también se extendió a intelectuales como Marcuse, Gadamer, Arendt, Rorty, Jonas, Binswanger, Boss, cuyas obras fueron un significativo aporte en diversas áreas del saber del siglo XX, como la política, la psicología, la historia o la biología.

6 Jaspers, K. Notizen zu Heidegger. Zürich: Serie Piper, 1989, p. 278.

7 Ibid, p. 172. 
ciego a las implicancias del gobierno de quien "no está preparado". Y esto es lo paradójico. No se trata de que Heidegger haya aplaudido a Hitler, el gestor de un régimen que acabaría con millones de vidas en Europa. En los años 30, la época en la que nos detendremos, aún no tienen lugar los crímenes masivos y las cruentas guerras ${ }^{8}$. Pero, aún así, Heidegger no representa al hombre corriente. En su persona se encarna el filosofar, y éste no parece ser sino la interrupción de la ingenuidad propia de la vida fáctica, haciendo suya sus propias tendencias, para ganar una orientación radical respecto del trato con el otro y con el mundo. Al menos esto es lo que tantos discípulos aprendieron del mismo Heidegger. Y, no obstante, quien entendiera el filosofar de esta manera es quien parece abandonar en sus escasas reflexiones políticas, casi arbitrariamente, tal nivel, y esto no sólo en esta anécdota, sino de facto, ciego al peligro inminente albergado en confiar la dirección del pueblo a Hitler.

¿Cómo es, pues, que deviene tal ceguera? ¿Más que la ceguera de un hombre, no se trata en este caso de una desorientación en el ejercicio del propio pensar? Digámoslo así: la ceguera de Heidegger a la que prestamos atención no se refiere a la incapacidad de predicción respecto de las consecuencias prácticas que implica apoyar un régimen totalitario. Su ceguera es más profunda aún. Refiere a la carencia de lucidez necesaria para advertir si la posibilidad de pensamiento que se emprende no puede sino ser en sí misma auto-aniquilante. Es una ceguera del pensar consigo mismo. El "caso Heidegger" es tanto más interesante, cuando se trata del despliegue de una particular posibilidad del pensar que parece descuidar su ejercicio en el ámbito político, sin advertir que con ello engendra su auto-anulación. En este caso, como se advierte, el problema que se discutirá no es el conflicto ético que supone la adhesión nacionalsocialista de Heidegger. A continuación, quisiéramos más bien indagar en las tendencias de tal ceguera. Nuestro interés es, pues, constatar algunas advertencias respecto al modo cómo el pensar de los Cuadernos Negros, en lo que refiere a la posición política ahí esbozada, pudo desorientarse tan radicalmente.

Ahora bien, nos centraremos en los años 30, una época en la que Heidegger se expresa con entusiasmo frente a la nueva situación política alemana, lo que coincide, a su vez, con la articulación de su propia posición filosófica. Nuestra tarea será rendir cuenta de estas dos dimensiones. Empero, se evitará recurrir a una dicotomía forzada como resulta escindir a Heidegger entre el filósofo y la persona, lo que ya Marcuse reconocía imposible de hacer ${ }^{9}, \mathrm{y}$, a la vez, no se pretenderá abordar el problema del nacionalsocialismo de Heidegger como si hubiese una dimensión práctica y, paralelamente, una dimensión teórica ${ }^{10}$, abstraída de la realidad, expresada como un Heidegger inexperto en la vida pública, que, víctima de su "analfabetismo político", pudiera haber tomado decisiones erradas. Quisiéramos, más bien, entender que hay, antes de nada, una estrecha relación entre un pensar filosófico y una convicción política, la cual también es un pensar. A nuestro juicio, las ideas políticas y los planteamientos filosóficos de Heidegger presentan una íntima coherencia en tanto que pensamiento único. Por tal razón, nuestro interés será esbozar el horizonte

\footnotetext{
Cfr. Stevenson, D. 1914-1918: Historia de la Primera Guerra Mundial. Buenos Aires: Debate, 2014, p. 731 s. Se trata de la carta escrita por Marcuse a Heidegger el 28 de agosto de 1947 (cfr. Marcuse, H. «Herbert Marcuse and Martin Heidegger: An Exchange of letters». New German Critique, 53, Durham: Duke University Press, 1991, pp. 28-32). Asimismo, cfr. Wolin, R. «Introduction to Herbert Marcuse and Martin Heidegger: An Exchange of Letters». New German Critique, op. cit., pp. 19-27.

10 Cfr. Rockmore, T. On Heidegger's Nazism and Philosophy, op. cit., p. 7.
} 
comprensivo que los integra coherentemente. En lo que sigue, por tanto, quisiéramos discutir que filosofía y convicción política en Heidegger atienden a un mismo problema, a saber: el del tiempo y la primacía del futuro. Para estos fines, no obstante, será necesario considerar algunos aspectos de la relación de Heidegger con la que fue su obra fundamental: Ser y Tiempo.

\section{La decepción de Ser y Tiempo: el abandono del presente}

La sección de notas referentes a 1931 de los Cuadernos Negros llama la atención sobre todo por la posición crítica que tiene Heidegger tanto respecto de su obra como de su recepción en la comunidad filosófica. Ambos aspectos pueden dar claridad acerca de la situación del pensar en la que éste se halla en los años 30.

En sus apuntes se lee: "Entonces bien, fue un malentendido de Ser y Tiempo poder superar la ontología directamente. El atroz 'éxito' sólo es, en efecto, que se parlotea más sobre el 'ser' y con menos suelo aún" ". Ser y Tiempo, la obra que debía replantear radicalmente la pregunta por el ser, acusaba su impotencia de generar un pensar auténtico y lo nefasto era que había despertado una habladuría acerca del asunto principal del filosofar. Se advierte aquí una auto-crítica de fondo expresada por el mismo Heidegger. Ser y Tiempo, en palabras suyas, "no está a la altura de la pregunta auténtica"12. El pensar ahí emprendido parece hallarse preso de ciertos prejuicios que terminarían por desorientarlo. Y la razón, a su juicio, radicaría en la incapacidad de haberse resistido a tres grandes tentaciones: la tendencia a fundamentar, propia del neokantismo; el enfoque en lo existencial, vinculable a Kierkegaard y Dilthey; y, por último, la cientificidad de la fenomenología ${ }^{13}$. Detengámonos, pues, en estos puntos.

Resulta claro que el programa de una analítica del Dasein no se anima sino desde la noción de "fundamentar". En efecto, el modo de proceder filosófico en juego en Ser y Tiempo consiste en realzar una estructura fundamental, aquella del "seren-el-mundo"14, desde la cual instancias existenciales fundadas en ella acusarán su genuino sentido. De esta manera, el pensar de Ser y Tiempo habría sucumbido a la tentación de entender que la filosofía "devela estructuras", i.e., realza "condiciones de posibilidad", como si se tratase de una "construcción" del campo temático sobre un suelo originario, mas donde aquel nivel último de fundación permanecería sin justificarse realmente ${ }^{15}$. Así, en tanto que fenomenología es "ciencia de los fenómenos" $"$, la tarea de este pensar constructor sería exponer con determinación científica un objeto temático que ha de ser "investigado", es decir, la tendencia de la fenomenología no pareciera sino radicar en un afán de "obtener conocimientos".

Como se advierte, tal autocrítica no se refiere precisamente a los contenidos de una cierta doctrina con la cual Heidegger estuviera insatisfecho. La objeción es más radical, se dirige al modo de ejercitar el pensar encarnado en Ser y Tiempo, a su propio método. Metódicamente, Ser y Tiempo sería un proyecto errado, pues se

\footnotetext{
11 Heidegger, M. Schwarze Hefte: Überlegungen II-VI (1931-1938). Frankfurt a. M: Vittorio Klostermann, 2014, p. 10 . 
sostendría en el supuesto de la cientificidad y de la fundamentación. Por tanto, los reparos son tales que, de ante mano, requieren principalmente de una superación total del punto de partida mismo que nutre a la obra. Finalmente, se habría terminado otorgando protagonismo a aquello que no era el tema auténtico del pensar que ahí se ejercía: el existir. En efecto, mientras éste último sería erradamente enfatizado, la pregunta por el ser mismo habría desaparecido. Para Heidegger, por el contrario, la tarea habría sido siempre: "[...] corresponder a la esencia del ser. Este es el sentido de aquella existencia auténtica que en 'Ser y Tiempo' es expuesta de modo aún demasiado 'existencial' y desde fuera" 17.

Pues bien, la exigencia por pensar el ser conduce a Heidegger a despreciar el ámbito del existir mismo, el principio metódico fundamental de toda su obra, pues, su peligro sería el hecho de redundar en el hombre, es decir, de constituirse en una antropologización y de volverse una mera pregunta por el existir ${ }^{18}$. Por esta razón, Heidegger puede llegar a hablar de una "ridiculez de la "filosofía existencial""19, lo que no querría decir otra cosa que éste, en retrospectiva, habría advertido un descuido profundo de la tarea auténtica de su proyecto. La pregunta filosófica por el ser no puede devenir en la pregunta por el ser humano, no puede permanecer siendo una filosofía existencial. Lo contrario sería el caso: desde una comprensión del ser se pueden inmediatamente fijar los límites de la pregunta por el hombre ${ }^{20}$. Por tanto, si se hubiese entendido que se trataba de un pensar acerca del ser: "entonces, no se habría podido malentender o abusar de 'Ser y Tiempo' como una antropología o una "filosofía existencial"'21. En lo anterior estriba la razón de la lejanía que expresa Heidegger frente a ese camino ${ }^{22}$. Un camino que terminaría por relativizar la ciencia y la trascendencia en función de la existencia ${ }^{23}$. Para Heidegger, el punto de partida se invierte. Ahora se trata de: "no fijar la pregunta por el ser en la 'existencia', sino en el comienzo en tanto que arrojarse a la esencia (Sichloswerfen ins Wesen)"

De esta manera, tales auto-críticas permiten entender, por otra parte, la disconformidad de Heidegger respecto de la recepción de su pensar. Como éste dirá: "Ser y Tiempo: la existencia se volvió meta y resultado, cuando era el medio y el camino" 25 . Es decir, mientras dicho pensar no era sino un "estar en trabajo" para acceder al auténtico asunto del pensar, habría sido entendido por la comunidad filosófica como un sistema acabado. Por lo mismo, no parece ser una afirmación del todo arrogante que Heidegger afirme: "Objeciones en contra del libro: hoy no tengo aún suficientes enemigos - éste no me ha traído un Gran Enemigo"26. Precisamente, ese "Gran Enemigo" debió de haber sido un lector lúcido de las pretensiones de

17 Heidegger, M. Schwarze Hefte: Überlegungen II-VI (1931-1938), op. cit., p. 56.

18 Cfr. Heidegger, M. Schwarze Hefte: Überlegungen VII-XI (1938/39). Frankfurt a. M: Vittorio Klostermann, 2014, p. 347: “Filosofía existencial' aún es antropología y metafísica; ella no pregunta la pregunta fundamental de la verdad del ser (Seyn) - ella no otorga ninguna decisión y, ante todo: ella no es decisión". Asimismo, cfr. Heidegger, M. Schwarze Hefte: Überlegungen XII-XV (1939-1941). Frankfurt a. M: Vittorio Klostermann, 2014, p. 88, donde Heidegger se expresa resueltamente en contra de un eventual "antropomorfismo".

19 Heidegger, M. Schwarze Hefte: Überlegungen II-VI (1931-1938), op. cit., p. 19.

20 Cfr. ibid., p. 53.

21 Ibid., p. 21.

22 Cfr. ibid., p. 20.

23 Cfr. ibid., p. 50.

24 Ibid., p. 94.

25 Heidegger, M. Schwarze Hefte: Überlegungen II-VI (1931-1938), op. cit., p. 74.

26 Ibid., p. 9. 
Ser y Tiempo, uno que hubiese advertido lo inadecuado del método, sin reparar en los meros resultados ahí expuestos. Pero nadie estuvo a la altura de objetar que la obra que debía elucidar y replantear la pregunta por el $\operatorname{ser}^{27}$, consolidando, así, una Ontología Fundamental, de la cual todo estudio regional emergería (entspringen) ${ }^{28}$, se volvería impotente. Ahora bien, es decisivo observar que la aludida incomprensión de su obra es entendida por Heidegger como un síntoma de la época misma. Es ésta, de hecho, la que no está a la altura de comprender su auténtico proyecto, ya sea por parte de quienes le elogiaron como de quienes la detractaron ${ }^{29}$. Por ello, junto a la inadecuada recepción y comprensión de Ser y Tiempo, aparece en el pensar heideggeriano de los Cuadernos Negros un rasgo muy particular, a saber, un juicio negativo del propio presente. En efecto, la situación actual del filosofar, del pensar mismo, es la que a sus ojos está en crisis: "El error de los de hoy; ellos no saben nada del largo y discreto crecer de las cosas y piensan por la noche forzar algún uso doméstico"30. El hombre de hoy es el impotente, y ha traído al ser "vasta habladuría y cada uno tiene el permiso, con igual derecho, de pensar lo que se le ocurra" 31 .

Así es como quisiéramos destacar una consecuencia relevante para las siguientes discusiones y que se vincula, a nuestro juicio, con una particular relación del pensar heideggeriano en general con su presente. Como se ha visto, éste emprende un alejamiento de la fenomenología. Dicho alejamiento, empero, implica que una confrontación constante con los fenómenos mismos, como el sustento fenoménico que avala el realce de momentos esenciales, parezca no ser ahora el camino adecuado. Justamente, dicha renuncia a la fenomenología es la que se vincula con otra renuncia por parte de Heidegger, a saber, aquella que dice relación con el ámbito de la existencia. Así, no es sólo que todo un programa filosófico pareciera quedar atrás, sino, más decisivo aún, que con la renuncia a la tendencia "científica" de la fenomenología y la renuncia al existir, como ámbito primario de consideración, se terminará por rechazar un modo de pensar que pretendía desplegarse siempre atento a un suelo de concreciones que le protegieran de no extraviarse de aquello que en efecto pretendía indagar: las cosas mismas. La renuncia heideggeriana trae, así, como consecuencia, que el filosofar mismo en torno al ser pueda ahora liberarse de la necesidad de buscar un suelo sobre el cual avanzar seguro, y, en este contexto, llega a entender que una aprehensión del ser puede realizarse de forma directa ${ }^{32}$.

Ahora bien, la destacada renuncia a lo inmediato, al existir mismo, no es, empero, una renuncia indiferente, sino que, por otro lado, parece nutrirse de un ánimo particular, a saber, de un abierto desprecio de la situación actual del pensar. En este último respecto, Heidegger anota, a modo de consigna: "Fuera de la locura de la habladuría de la situación, en la alejada preservación del poder del origen" 33 . $\mathrm{Y}$ es que para el nuevo pensar heideggeriano el presente no sólo deja de ser aquel

\footnotetext{
Cfr. Heidegger, M. Sein und Zeit, op. cit., p. 4.

Cfr. ibid., p. 13.

Cfr. Heidegger, M. Schwarze Hefte: Überlegungen II-VI (1931-1938), op. cit., p. 20.

Ibid. p. 28.

Ibid. p. 9.

32 Fink comentará sobre la lección Von Wesen des Grundes: "Ella [la lección] viene a significar, a mi juicio, [...] el auténtico desprendimiento de Heidegger de la fenomenología y la irrupción en un modo del pensar ontológico completamente propio, el cual ya no gana su rigurosidad y profundidad especulativa en la descripción de fenómenos ónticos, sino que pasa resueltamente al ser del ente" (Cfr. Fink, E. Welt und Weltlichkeit. Würzburg: Königshausen \& Neumann, 1990, p. 168).

33 Heidegger, M. Schwarze Hefte: Überlegungen II-VI (1931-1938), op. cit., p. 20.
} 
ámbito requerido para erigir el auténtico pensar, sino que, más aún, parece ser un ámbito de decadencia, que, sin más, debiera ser superado ${ }^{34}$. Así, por lo pronto, queremos destacar que el pensamiento del Heidegger de los Cuadernos Negros parece motivarse por un abandono de la inmediatez en el contexto de un resuelto desdén por el presente, lo que, a nuestro juicio, se torna un elemento fundamental para entender aquel horizonte comprensivo en el que se integra su posterior adhesión al Nacionalsocialismo. El filosofar de Heidegger parece desligarse de las "cosas mismas", dadas en el mismo existir, despreciando, además, el presente, y con todo ello, parece perder la necesidad de avanzar apoyado en un suelo cierto de concreción fáctica para ahora acceder directamente al ser. Justamente, descuidando lo presente e inmediato, el pensar heideggeriano parece ser conducido peligrosamente más allá de la contingencia efectiva.

\section{La primacía del futuro y la imposición de un "destino propio"}

En principio, el pensar heideggeriano de los Cuadernos Negros parece motivarse por un afán de transformación del presente. El estado actual del saber estaría arruinado, las ciencias del espíritu se encontrarían en desgracia, anegando, desvaneciendo y debilitando todo lo espiritual ${ }^{35}$. No obstante, resulta interesante advertir que la trasformación aquí concebida parece emerger desde un supuesto por parte de Heidegger que es la relación presupuesta entre el ser y el hombre. La manera como Heidegger entiende tal relación y a ambos componentes implicados en ella es lo que le otorga un rasgo característico a su pensar. Ésta es discutida al modo de una anhelada unificación, de una auténtica apropiación. El ser humano radica, en esencia, en una apropiación del ser, dado que la esencia del mismo es, en sí, un "silente apoderamiento" ${ }^{36}$. El hombre es tal, por tanto, en este movimiento de inserción en el "acontecimiento del ser" (Seinsgeschehnis) ${ }^{37}$. Empero, comprender al hombre desde el poder y dominio del $\operatorname{ser}^{38}$ no sólo delimita su propia esencia, sino que ella implica, a la vez, la prescripción para lo humano de un deber que le ha de pertenecer según su propia naturaleza.

Coherente con determinar la naturaleza humana desde el ser, abandonando, por cierto, toda idea de subjetividad, ya sea al modo clásico de un animal rationale, y entendiendo ahora al hombre desde el movimiento total de un "apoderamiento", su auténtico ejercicio se expresaría consagrando una alianza con el ser. En este contexto es en el que se advierte una dimensión más bien normativa en el pensamiento heideggeriano, en cuanto subyace implícita la prescripción de un deber que, por su parte, es criterio para discernir si el hombre es, en última instancia, responsable o irresponsable de sí mismo. Visto desde esta perspectiva, el por Heidegger llamado "hombre de hoy" no es sólo ignorante respecto del ser, sino que con su "parloteo

\footnotetext{
34 Se trata de una denuncia, por parte de Heidegger, de una "decadencia espiritual" destacada por Derrida y que discutiremos más adelante. Cfr. Derrida, J. «Del Espíritu». Tres textos sobre Heidegger. Abensour, Levinas, Derrida. Santiago de Chile: Ed. Metales Pesados, 2006, p. 112.

35 Cfr. ibid. p. 99.

36 Cfr. ibid. p. 55.

37 Cfr. ibid. p. 57.

38 Cfr. ibid. p. 94.
} 
vacío" se vuelve igualmente irresponsable de su propia esencia ${ }^{39}$. El presente se caracteriza, entonces, por una irresponsable desapropiación del ser, y por ello no sólo debe ser superado, sino, ante todo, reformulado. En consecuencia, la relación con el presente no es meramente transformadora, sino que acusa una tendencia decididamente normativa.

Ahora bien, ¿dónde ha de ejercerse la responsabilidad propia de lo humano? Aquí es donde se integra la historia como un asunto central en los apuntes heideggerianos. El hombre debe aclararse sobre la historia de la des-apropiación (Entmächtigungsgeschichte) y, así, prepararse para la apropiación de la esencia (Ermächtigung des Wesens) ${ }^{40}$. Dicho acontecimiento es uno fundamentalmente de carácter histórico, ya que el eje de discusión se concreta históricamente, a saber, en cuanto: realizar un "comienzo originario"41, una "nueva realidad"42. Y es que la historia del des-empoderamiento de la esencia del ser habría llevado a que la ontología, el pensar filosófico por excelencia, se constituyera en un desafortunado "fortalecimiento" y "santificación" del mismo ${ }^{43}$. La responsabilidad humana se traducirá, en cambio, en la necesidad de un retorno apropiador hacia el ser.

Por cierto, las tesis fundamentales halladas en los Cuadernos Negros son reconocibles ya en Ser y Tiempo. Ahí es donde el problema de la subjetividad se plantea en términos temporales, es decir, donde se realza la esencia de lo humano en su historicidad. La segunda parte de dicha obra privilegia precisamente la temporalidad como el horizonte propio del ser del Dasein. El ser del Dasein es el cuidado (Sorge) ${ }^{44}$, es decir, Dasein es, en cuanto tal, la concreción fáctica, al modo de abrir su mundo, desde una posibilidad determinada, la misma que es entendida como el sentido articulador del presente, esto es, del ahí en el que habita el existir. Este movimiento de apertura desde la posibilidad abrirá al Dasein, a su vez, a lo que "ahí-ha-sido" (da-gewesen), esto es, a su pasado ${ }^{45}$. El Dasein, entonces, es su pasado y la comprensión de su haber-sido, podríamos decir, en el proyecto primario a su posibilidad. Por ello, el futuro ha de mostrar la auténtica primacía en estos planteamientos, pues éste es límite del presente y del pasado, es configurador de mundo en tanto que horizonte de apertura del ente con el que "ya siempre se ha encontrado" en un trato actual y efectivo. En consecuencia, es desde el futuro desde donde habrá que entender el pasado propio, la auténtica historia ${ }^{46}$.

Las anotaciones de Heidegger próximas a su período de rectorado son coherentes con estas consideraciones, y, de forma invariable, se advierte el futuro como el sustento principal de su nuevo pensar. Sin embargo, las que en Ser y Tiempo parecen ser indicaciones formales, alusiones a estructuras de un existir "puro", en las anotaciones discutidas todo parece configurarse en términos políticos. Este aspecto

39 Así es como Steinbock alude a la posibilidad de apropiación del hombre en el ser y a su desapropiación en la mecanización como contexto del pensamiento nacionalsocialista heideggeriano y de su postura antisemita (Cfr. Steinbock, A. «Machination, and the Jewish Question: the problem of the gift». Gatherings: The Heidegger Circle Annual, 5, 2015, pp. 50-76). Asimismo, cfr. Trawny, P. Heidegger y el mito de la conspiración mundial de los judios, Barcelona: Herder, 2015.

40 Cfr. Heidegger, M. Schwarze Hefte: Überlegungen II-VI (1931-1938), op. cit., p. 90.

41 Cfr. ibid., p. 17.

42 Cfr. ibid., p. 72.

43 Cfr. ibid., p. 89.

44 Cfr. Heidegger, M. Sein und Zeit, op. cit., § 41.

45 Cfr. ibid., $§ 68$.

46 Cfr. ibid. p. 395. 
llama la atención. Aquel futuro rector y horizonte de la apertura del ahí, esta vez se traduce en un concepto fundamental: el "destino", por cierto, de carácter políticohistórico ${ }^{47}$. Asimismo, desde estas categorías político-históricas, lo que en Ser y tiempo es el existir apropiado de sí, se traduce ahora en el "pueblo", en la "nación" "48, mientras que "la masa" se presenta como un conglomerado de ciudadanos "sin historia" $"$ 9.

La discusión pasa a concretarse en los Cuadernos Negros en términos del "pueblo" y de su relación con el "destino" 50 , pues este es el movimiento que le será necesario para ganar su "esencial particularidad" (wesentliche Vereinzelung) ${ }^{51}$, esto es, la alemanidad (Deutschheit) ${ }^{52}$. Ella es, pues, el nuevo estado que se obtendrá mediante el empoderamiento del ser. Por ende, si en un momento la tradición alemana pudo haber sido entendida como una directa heredera de la tradición griega, la apropiación de la alemanidad mediante el enraizamiento en su destino le exige elevarse en su más propia identidad y consolidar su eminente autonomía. Ya no se trata de revitalizar la antigüedad. Heidegger se pregunta: " $\mathrm{o}$ antes debe reatarse la cinta con los griegos?"53. Lo mismo se expresa en términos disciplinarios: "la así llamada 'filología clásica' ahora tiene sólo la tarea de poner a disposición, esto es, de desplegar con la mayor fuerza posible lo latino y griego para la más ardua y esencial confrontación posible de lo alemán con ellos" ${ }^{\prime 5}$. En términos de la identidad histórica, esto implica que Alemania, es decir, la nueva condición de unidad en cuanto "pueblo y nación" 55 , se vuelva ella misma la medida de lo otro.

Como se advierte, finalmente, lo que está en juego en tales planteamientos son los esquemas de pensamiento que asumen al futuro como la instancia última, como condición de posibilidad de apertura del ente en su totalidad, en este caso, del pueblo alemán con su propia situación epocal. La confrontación con el pasado desde su futuro es, en última instancia, parte de una orientación en la historia del ser y en la historia fáctica de Europa, y es que sólo aquel pueblo con una tradición tan particular es quien puede asumir dicha tarea espiritual: "¿o lograremos -interroga Heideggeruna nobleza espiritual real que sea suficientemente fuerte como para configurar la tradición de los alemanes a partir de un gran futuro?"56.

Así es como movimientos formales del existir, descritos en Ser y Tiempo, se concretan en categorías político-históricas, propias de la situación de la Alemania de la época. El movimiento existencial del proyecto al futuro para la apropiación de sí se encarna ahora en la comprensión del pueblo alemán en vistas a su destino históricopolítico $^{57}$. Pese a lo políticamente concretas que resulten las ideas que comienzan

47 Cfr. Heidegger, M. Schwarze Hefte: Überlegungen II-VI (1931-1938), op. cit., p. 100.

48 Cfr. ibid., p. 92.

49 Cfr. ibid. 114. En este contexto, Adrián vincula la relación heideggeriana entre "pueblo" y "destino" a sus lecturas de Paul Yorck von Wartenburg. Para éste el existir no sería un individuo, sino una generación, es decir, un "pueblo". Por ende, su destino no sería uno particular, sino que es el de una colectividad (cfr. Adrian, J. «Heidegger's Black Notebooks and the Question of Anti-Semitism». Gatherings: The Heidegger Circle Annual, 5, 2015, p. 32 s.).

50 Cfr. Heidegger, M. Schwarze Hefte: Überlegungen II-VI (1931-1938), op. cit., p. 97.

51 Cfr. ibid., p. 98.

52 Cfr. ibid., p. 101.

53 Ibid., p. 101.

54 Ibid., p. 124.

55 Cfr. ibid., p. 92.

56 Ibid., p. 121.

57 Cfr. Heidegger, M. Schwarze Hefte: Überlegungen VII-XI (1938/39), op. cit., pp. 196-199. 
a esbozarse en los Cuadernos Negros, ellas no aparecen sino en el contexto de la noción preconcebida de futuro y destino. El pensamiento de Heidegger no sólo parece desdeñar el presente en general, sino también un presente político concreto, y es a este al que se le pretende imponer un ideal de destino histórico, avalado en la comprensión de que la historicidad humana es un movimiento eminentemente futuro. Es, pues, en este contexto de comprensiones donde finalmente se articularán posiciones políticas concretas como la propia idea de universidad del Heidegger rector y, por cierto, donde se nutre fundamentalmente la esperanza en el Nacionalsocialismo. Esta concreción última del pensar del ser y del destino, en su configuración ideológica política tan concreta como resulta ser la adhesión al Nacionalsocialismo, es justamente el punto que a continuación deberemos discutir.

\section{La reformulación universal del presente: la educación nacionalsocialista}

Se ha señalado que para Heidegger el presente es lo que debe ser corregido y que tal corrección proviene de una apropiación, por parte del pueblo alemán, de su auténtico destino. Las expresiones políticas de los Cuadernos Negros encarnan dicho planteamiento. Para el Heidegger rector de la Universidad de Freiburg, año 1933, todo redunda en concebir una idea de "universidad" coherente con este movimiento temporal. Ahora bien, su implementación no podría tener lugar sino bajo circunstancias políticas propicias. Aquellas, de hecho, que sólo se ofrecen con la asunción del poder del Nacionalsocialismo. Dicho régimen sería el aval y garante de la tan anhelada resolución del pueblo a su destino. Por ende, universidad y Nacionalsocialismo no son sino dos instancias íntimamente relacionadas entre sí. Detengámonos, pues, en su relación.

El inicio del semestre de invierno de 1933/34 Heidegger habla del Nacionalsocialismo y la guía de Hitler en términos de la "revolución nacional socialista" 58 . Dicha revolución, proclamada en la autoafirmación de la universidad alemana, encarna la esperanza de una nueva época, aquella que él entiende como el nuevo "mundo espiritual de un pueblo", i.e., "el poder de la más profunda custodia de sus fuerzas terrenales y sanguíneas" 59 . Este "nuevo mundo" concebido por Heidegger no es, por cierto, aquel que se hallaría en niveles "fundados", "no originarios", de la realidad, como lo serían la cultura o un sistema de conocimientos académico-científicos. Este nuevo mundo es, ante nada, una nueva situación espiritual y política. Y es que en términos políticos, la revolución traería consigo el estado nacional socialista, pero a su vez, en términos espirituales, ésta implicaría la "completa reformulación de nuestro existir alemán"60.

Así, el pensar de Heidegger entiende que tal revolución ha de ser una actitud vital tan concreta que finalmente se manifieste en una circunstancia política efectiva. En su carta a Marcuse de 1948, Heidegger comenta que él esperaba del Nacionalsocialismo "una renovación espiritual de la vida completa", es decir, aquella rearticulación

58 Cfr. Heidegger, M. «Zum Semesterbeginn (3. November 1933)». Rede und andere Zeugnisse eines Lebensweges. Frankfurt a. M: Vittorio Klostermann, 2000, p. 184.

59 Heidegger, M. «Die Selbstbehauptung der deutschen Universität». Rede und andere Zeugnisse eines Lebensweges, op. cit., p. 112.

${ }^{60}$ Heidegger, M. «Ansprache am 11.November 1933 in Leipzig».Rede und andere Zeugnisse eines Lebensweges, op. cit., p. 192. 
existencial que mencionábamos anteriormente. Empero, en términos políticos, sus esperanzas también eran las de "reconciliar las oposiciones sociales y salvar al existir occidental de los peligros del comunismo" ${ }^{2}$. Sería, entonces, la decadencia del presente de la cual Heidegger estaba convencido lo que sostiene sus esperanzas en el Nacionalsocialismo, pues, al radicar en una desorientación completa respecto del empoderamiento del ser, dicho presente se expresa en una decadencia política y social efectiva.

En efecto, después de renunciar al rectorado en abril de 1934, y en señal de oposición al régimen, según lo comenta a Marcuse en la mencionada carta, Heidegger realiza paradójicamente dos conferencias cuyo tema central es la universidad alemana, el 15 y 16 de agosto del mismo año ${ }^{62}$. Se trata de una reconstrucción histórica de la gestación de la universidad alemana en el siglo XIX. Interesante es el hecho de que Heidegger conciba ahí la industrialización como un momento histórico con consecuencias nefastas, en cuanto da paso a la división de proletarios y burgueses y a la natural división del pueblo alemán en clases y partidos políticos. Así, el responsable de esa nueva configuración política es identificado de inmediato en términos de una "revuelta marxista" de fines del siglo XIX ${ }^{63}$. Heidegger afirma:

El 'trabajador' no es, como quisiera el marxismo, el mero objeto de la explotación por parte de la clase dominante. [...]. El trabajo no es ni una mercancía ni sirve sólo para la producción de bienes para otros. Trabajo tampoco es sólo la ocasión y el medio para ganar un sueldo. ${ }^{64}$

En estas palabras se conjuga la problemática tanto política como espiritual que advierte Heidegger. El marxismo es un pensar lejano de la actitud de apropiación del ser. Este hace ver el trabajo como un mero producto, perdido en la decadencia de la contingencia. En dicho afán, su orden político implica llevar a sus ciudadanos a desperdigarse en el mero hacer, convirtiéndolos, de hecho, en masa, es decir, individuos carentes de toda unidad real. Así, el comunismo, su correspondiente configuración política, traería consigo un peligro espiritual, pues no parece sino animarse por la des-apropiación del ser en cuanto "maquinación" (Machenschaft), traduciéndolo todo en tener y lo tenido ${ }^{65}$. Así, un pensar des-enraizador como el marxismo es el que alberga en sí un orden social decadente como el comunismo.

Ahora bien, la respuesta a esta actitud espiritual y a su expresión política no es otra que la de comprender radicalmente que todo trabajar está determinado por una "disposición" (Gesinnung), una "actitud" (Haltung) y una "comprensión del trabajo" (Werkverständnis)" "66. Todo trabajo nace, por lo mismo, de un sentido espiritual. Dicha "espiritualidad" es el centro de la discusión, pues, en tanto que actitud, es lo que Heidegger vincula con la nueva realidad, aquella que superaría la

61 Heidegger, M. «Zu 1933-1945 (Brief an Marcuse, 20. Januar 1948)». Rede und andere Zeugnisse eines Lebensweges, op. cit., p. 430.

62 Heidegger, M. «Die deutsche Universität (15./16. August 1934)». Rede und andere Zeugnisse eines Lebensweges, op. cit., pp. 285-307.

$63 \quad$ Ibid, p. 297.

64 Ibid., p. 303.

65 Cfr. Heidegger, M. Schwarze Hefte: Überlegungen XII-XV (1939-1941), op. cit., p. 149 s.

${ }_{66}$ Cfr. Heidegger, M. «Die deutsche Universität (15./16. August 1934)». Rede und andere Zeugnisse eines Lebensweges, op. cit., p. 303. 
fatalidad que representa el marxismo ${ }^{67}$. Por lo mismo es que la lucha de Heidegger no puede articularse como la propuesta de un mero orden político, pues antes de éste ha de darse una disposición desde la cual todo se reorganice. Esto lleva a desligar lo "espiritual" de una instancia ajena a la praxis y la concreción mundana. Lo "espiritual" es, como Heidegger mismo lo indica, una abreviación de la expresión "esencia íntima" (inneres Wesen) ${ }^{68}$. Lo espiritual es, ante todo, un modo de existir que identifica a un pueblo, un ethos originario, podríamos decir, que se articula en un orden político. Esta nueva disposición espiritual que Heidegger anhela, la apropiación del destino, es aquella que se manifestaría en el gobierno de Hitler. Así, la "revolución nacionalsocialista" a la que Heidegger apela en sus discursos no es sino la síntesis de esta nueva actitud espiritual y su corporeización política, la misma que podría superar la decadencia actual. En otros términos, porque el presente debe ser corregido, se entiende el entusiasmo al pensar que el Führer reconducirá al pueblo de su "auto-perdición" a "su propia determinación" y a "su nueva voluntad de existir" ${ }^{\prime \prime}$.

Con esto no queremos sino señalar que el Nacionalsocialismo y la adhesión a Hitler se integran en el pensar heideggeriano en el contexto de una privación. Ellos parecen ofrecer la posibilidad de que el presente sea finalmente como debiera ser, pero que aún no es. Las medidas propositivas del Heidegger rector de la universidad de Freiburg son, por tanto, medidas correctivas de la situación contingente, negada por completo y de antemano desde la idea de aquel presente resultante de una actitud espiritual radical. La noción de educación que mueve al Heidegger rector es, así, la unidad del saber. Pero no se trata de una mera unidad formal, sino de la consolidación de un saber unitario que promueva la unión del pueblo. Más allá de "capsulas de saberes disciplinarios ciegos" ${ }^{\text {" }}$, propios de la concepción cientificista, todo radica para Heidegger en la superación de la ciencia y su división en especialidades, pues, lo que se busca es una sabiduría apropiadora, que conecte al pueblo con su historia y lo abra a su futuro. Esta nueva sabiduría es, a fin de cuentas, el motor de la revolución hacia una nueva realidad. Para Heidegger la revolución es una producción ${ }^{71}$. Esta

${ }_{67}$ Rocha de la Torre advierte que el marco de problemas desde los cuales se deja entender la adhesión de Heidegger al Nacionalsocialismo se relaciona directamente con su crítica a la técnica. Reparando en ella, a su juicio, sería posible objetar la tesis de Emmanuel Faye, que entiende la filosofía total de Heidegger como un pensar dependiente de la ideología nazi (cfr. Rocha de la Torre, A. «Heidegger: ¿introducción del Nacionalsocialismo en la filosofía? Una reflexión en contravía». Franciscanum: Revista de las ciencias del Espíritu. 162, LVI, 2014, pp. 19-49). A la vez, y en el mismo contexto de la técnica y su calculabilidad, el repudio heideggeriano al marxismo se centra en su actitud calculadora, aquella que habría fortalecido la industrialización y su consecuente exigencia de producción (cfr. Heidegger, M. «Die deutsche Universität (15/16. August 1934)». Rede und andere Zeugnisse eines Lebensweges, op. cit., p. 295).

68 Cfr. Heidegger, M. «Die deutsche Universität (15./16. August 1934)». Rede und andere Zeugnisse eines Lebensweges, op. cit., p. 289. Asimismo, cabe destacar el cambio en el uso de la palabra "espiritual" (geistig) en su transición de Ser y Tiempo al discurso de rectorado La autoafirmación de la universidad alemana. Como lo destaca Derrida, mientras en la primera obra hay una suerte de prudencia, que éste advierte en el uso entre comillas de este término, en el discurso tales comillas desaparecen, "se levanta el telón", lo espiritual aparece resueltamente como el tema fundamental heideggeriano. Cfr. Derrida, J. «Del Espíritu». Tres textos sobre Heidegger. Abensour, Levinas, Derrida, op. cit., pp. 93-96.

69 Ibid., p. 297.

70 Cfr. Heidegger, M. Schwarze Hefte: Überlegungen II-VI (1931-1938), op. cit., p. 117.

71 Cfr. ibid., p. 112. 
es la razón por la cual éste redunde en la "destrucción"72, "muerte"73 o fin ${ }^{74}$ de la universidad, a cambio de una "educación del saber" (Wissenserziehung) ${ }^{75}$.

La primacía de la universidad en la revolución nacionalsocialista gana su derecho, como se advierte, en la idea del movimiento total del pueblo alemán hacia su destino. Ella es, pues, la instancia unificadora de lo alemán en vistas a superar su estado actual de "masa". Mientras Heidegger anota " "la masa» - ninguna comunidad del pueblo"" éste concibe, a la vez, una "Academia del Saber" (Wissensakademie) mediante la cual se garantice la unificación de lo alemán en el horizonte del destino. Por ello, la enseñanza se dirigirá a todos en cuanto uno, a todos en tanto que pueblo resuelto a un destino. Desde la noción de futuro parece motivarse, entonces, la idea de que tal educación sea concebida como la instancia de contención identitaria del pueblo. En consecuencia, educar para el destino es metapolítica, es decir, la conducción a una comunidad auténtica. Aparece, de esta manera, la idea de una "metapolítica 'del' pueblo histórico" "77. Metapolítica es, en fin, el nombre para el direccionamiento total de la comunidad, una idea que pareciera confirmar en el pensar heideggeriano de los Cuadernos Negros un afán normativo que, a su vez, poseería una pretensión universal.

Este es un punto clave para nuestras discusiones. Como se advierte, Heidegger no parece estar convencido de que el nuevo mundo que emergería del Nacionalsocialismo ya haya llegado. Más bien, él parece proclamar la nueva realidad generando las condiciones educativas universales en su beneficio. Sin embargo, todo esto se realiza en el contexto de una concepción más bien anhelada del destino. Asimismo, la situación decadente del presente, que no es sino comprendida desde la esperanza en este futuro deseado, se muestra en el centro de las discusiones heideggerianas. Mas el hecho de que dicho presente sea considerado en decadencia no parece sino motivarse desde un bonum futurum entendido como redentor. Así es como la concepción de este complejo aparataje de movimientos fundamentales trae consigo un insoslayable peligro, a saber, que las ideas correctivas de la realidad contingente no respondan sino más bien a una apuesta articulada desde un pensar que ha descuidado un examen de lo inmediato. El pensar político de los Cuadernos Negros parece, así, haber dado un salto directo a instancias superiores, no obstante, a la vez, ha perdido todo suelo concreto, políticamente contingente y fáctico, sobre el cual avanzar seguro ${ }^{78}$.

\section{Auto-anulación del pensar: el llamado lábil a la auto-apropiación}

Se ha discutido cómo es que la situación del pensar heideggeriano, en su desvinculación con Ser y Tiempo, ha asumido determinadas tendencias. Se advirtió

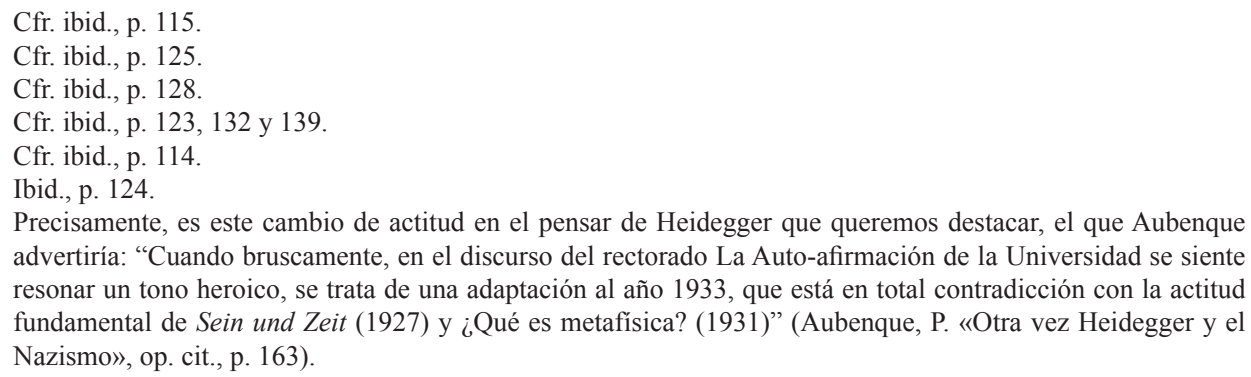
advertiría: "Cuando bruscamente, en el discurso del rectorado La Auto-afirmación de la Universidad se siente resonar un tono heroico, se trata de una adaptación al año 1933, que está en total contradicción con la actitud fundamental de Sein und Zeit (1927) y ¿Qué es metafísica? (1931)" (Aubenque, P. «Otra vez Heidegger y el Nazismo», op. cit., p. 163). 
que éste se despliega en el marco del abandono de la fenomenología y de su cientificidad. Se ha visto, además, cómo se mantiene y se acentúa la idea de futuro como horizonte último de concreción del presente. Dos elementos aparecían en este pensar: el desprecio por el presente fáctico y un afán de corrección del mismo en vistas a un destino de carácter espiritual/político. Tal movimiento, se observaba, se concebía como un plan universitario de restauración, coherente con la idea de destino histórico que ya ha asumido caracteres normativos, es decir, que se impone como un deber ser. De ahí se pudo entender la noción heideggeriana de metapolítica como una rectificación universal. Su necesidad radicaría en educar a un pueblo en vistas a ganar su identidad y a superarse en tanto que "masa".

Mientras tanto, en julio de 1933, con la asunción al poder de Hitler, ya se habían eliminado todos los partidos políticos en el Reichtag. Por razones antisemitas y políticas, el despido de académicos como Cassirer, Geiger, Plessner, Horkheimer, Adorno y otros $^{79}$ se implementaba con decisión. En Freiburg, desde marzo del mismo año, se emprendía la persecución de miembros del partido comunista, social demócrata y de sindicalistas. El 13 de marzo el alcalde Josef Hölzl y el miembro del consejo municipal, Franz Geiler, son tomados presos. La propaganda antisemita venía siendo públicamente difundida. Empero, no hay alusiones por parte de Heidegger a medidas concretas del gobierno del Führer. Este no aplaude estrategias políticas contingentes. Su preocupación parece radicar más bien en dar índices acerca del filosofar, de recuperar las raíces en el acontecimiento mismo del ser y de entender el contexto político como el desarrollo de un movimiento espiritual superior. La contingencia pareciera no ser digna de atención en vistas a un acontecer originario $\mathrm{y}$, en caso de que esto sí ocurriese, las circunstancias son presentadas al servicio de tal acontecer ${ }^{80}$. En efecto, en el marco de los movimientos históricos, las notas de los Cuadernos Negros no integran al Nacionalsocialismo y a Hitler como los auténticos protagonistas, pues no lo son. El Nacionalsocialismo heideggeriano no tiene que ver con Hitler, sino con su apuesta a una determinada idea de futuro y destino. El Führer y su revolución nacionalsocialista carecen de toda concreción fáctica, no son sino meros medios en el contexto de movimientos originarios. Heidegger mismo, en cuanto rector, no parece atribuirse un poder particular. Él figura más como un vigía a cargo de velar por una educación, por una formación espiritual apropiada. Así, a las ideas expresadas por Heidegger subyace una sumisión decidida a un proyecto último, a saber, el de la ejecución final del destino, pues dicha ejecución es su auténtica preocupación.

Lo anterior lleva a entender que las expresiones políticas de Heidegger no tengan una motivación eminentemente política, sino más bien metafísica. Con esto, empero, no afirmamos que sus ideas políticas se apoyen "doctrinariamente" en "teorías" filosóficas de carácter metafísico, como bien se podrían identificar en sus

79 Cfr. Sluga, H. Heidegger's Crisis: Philosophy and Politics in Nazi Germany. Cambridge: Harvard University Press, 1995, p. 2.

80 Incluso comentarios sobre "lo que se llama geográfica-políticamente las democracias del este" son planteadas por Heidegger en términos de movimientos superiores espirituales. En ellas no habría decisiones respecto de una meditación sobre otro comienzo de la historia del ser (cfr. Heidegger, M. Schwarze Hefte: Überlegungen VII-XI (1938/39), op. cit., p. 405 s.). Steiner, a su vez, señala que en los mismos discursos nazis de Heidegger, en su "autoafirmación de la universidad", es la primacía ontológica del "auto" el tema auténtico de discusión y no lo político fáctico (cfr. Steiner, G. Heidegger. México D. F.: FCE, 2005, p. 177 s.). 
planteamientos influencias del pensamiento griego y del idealismo alemán ${ }^{81}$. Más bien afirmamos que el motor último del despliegue del pensar correctivo heideggeriano se nutre de la idea de que, en efecto, hay un movimiento "trans-físico" que corresponde al devenir del destino sobre un pueblo que se ha apropiado de sí mismo. Justamente es desde esta óptica que ya no es posible distinguir a un Heidegger filósofo y uno inexperto de la vida práctica, porque no se trata de una relación entre teoría y su incidencia en la praxis. A nuestro juicio, en los Cuadernos Negros siempre se ha tratado de un pensar. Aquel que, a veces, permanece en un nivel de formalidades, indeciso respecto de su concreción material, para luego traducirse, según su lógica interna, en una ideología determinada.

Llama la atención, sin embargo, cómo es que tal pensar no advierte el peligro que él mismo alberga. Detengámonos en este punto. Cuando señalamos que el pensamiento de Heidegger albergaría en sí mismo un peligro, no nos referimos al hecho de que éste habría "errado" al apoyar al régimen político que traería la ruina en la Europa de la primera mitad del siglo XX. No se trata de "peligro" en el sentido de un juicio de valor ${ }^{82}$. Cabe recordar que el contexto de las presentes discusiones son los años 30, cuando la estrategia bélica de Hitler aún no se hacía evidente. Las discusiones señalan otro peligro: uno que es interno al pensamiento mismo que se despliega en los Cuadernos Negros. Es aquel que también resuena en el comentario acerca de las manos de Hitler, esto es, observar la contingencia, prestando atención a aspectos superfluos, como si, en realidad, no se la tuviera en cuenta. El pensamiento político de los Cuadernos Negros pareciera estar igualmente desenfocado de lo que hay que leer en la situación concreta. Precisamente, en dicho desenfoque estriba el peligro que deseamos señalar.

$\mathrm{Y}$ es que la nueva configuración del pensamiento heideggeriano adquiere un carácter fuertemente especulativo, articulándose en vistas a movimientos epocales. Con ello, el pensar desplegado en los Cuadernos Negros ha ido "más allá" de los hechos y parece erigirse sobre arriesgadas presunciones. Se ha vuelto una consideración de instancias superiores, de cuya evidencia nada hay, en absoluto. Es decir, justo cuando se le exige la radicalidad suficiente como para ganar una orientación en el aquí y ahora, ya que la contingencia política advierte sobre riesgos reales, el pensar de Heidegger se encuentra absorto en instancias abstractas, que parecieran enceguecerlo respecto de lo que ocurre. Así y todo, son tales apuestas las que se constituyen en la medida desde la cual el presente es concebido y desde ellas es que se pretende corregirlo. Esta pretensión normativa de la contingencia pierde de vista las circunstancias, cuando sería lo que ellas muestran el mejor criterio para evaluar lo que efectivamente ha de corregirse. Tal pensamiento ha abandonado

81 Rockmore reconduce los fundamentos metafísicos del pensamiento político-universitario de Heidegger a Platón y Hölderlin (cfr. Rockmore, T. On Heidegger's Nazism and Philosophy, op. cit., pp. 54-72 y pp. 126-133). Por su parte, Aurenque caracteriza la posición política heideggeriana como un proyecto político románticoplatónico (Cfr. Aurenque, D. «Heidegger y el “enredo” de la filosofía con la política: sobre su origen románticoplatónico». Revista de Filosofía, 66, 2010, pp. 195-213.). Sluga da énfasis a la relación de Heidegger con los Discursos a la nación alemana, de Fichte, y su idea de educación (cfr. Sluga, H. Heidegger's Crisis: Philosophy and Politics in Nazi Germany. Cambridge: Harvard University Press, 1995, pp. 34-41).

82 Como es el caso de Marcuse quien, a nuestro juicio, representa la posición de muchos intelectuales que condenaron y condenan la adhesión de Heidegger al régimen de Hitler: "Hoy en día se ve inexcusable desechar el apoyo de Heidegger al régimen de Hitler como un equívoco o error. Creo que un filósofo no puede cometer tal 'error' sin que con ello niegue su propia, auténtica filosofía” (Marcuse, H. «Postcript: My disillusionment with Heidegger». Heideggerian Marxism, London: University of Nebraska Press, 2005, p. 176). 
el lugar donde debería acontecer, el estricto apego a las cosas mismas, y aun así pretende normar aquello para lo que él es ciego.

Digámoslo así: programáticamente, este nuevo pensamiento se aleja de la fenomenología, pero, respecto a su propia posibilidad, él renuncia a la condición fundamental para todo pensar acerca de algo: un suelo de inmediatez desde el cual nutrirse para no perderse en meros fantasmas. Así, su peligro inherente es su propia auto-anulación. Su carencia de apoyo le anula en su auténtica posibilidad de pensar ${ }^{83}$. Es un hecho que en las anotaciones de los años 30 abundan las palabras futuro, destino, más no hay una descripción estricta de ellos. Mientras que redundan expresiones con aires de redención, dicho destino parece ser una representación vaga. La revolución nacionalsocialista que es entendida por Heidegger como el remedio en contra de la decadencia del presente no parece ser más que un ideal que se nutre, ante todo, de un anhelo, el mismo que se habría encontrado tan difundido entre los ciudadanos alemanes tras la Primera Guerra Mundial: devolver a Alemania su identidad perdida, como lo destaca Patočka ${ }^{84}$, comentando la entrevista de Heidegger en Der Spiegel ${ }^{85}$.

Así, pese a que el pensar político que aparece en los Cuadernos Negros da la impresión de implicar un bienestar último y altruista, apelando a una apropiación histórica en favor del propio pueblo, él mismo, i.e., este mismo pensar, desde el vacío del anhelo que lo motiva, no se hace cargo de lo que pretende ser: creyendo desplegarse seguro, no advierte que su anhelo es el que le ha llevado a perder de vista la fragilidad de su ejecución. Esto lleva a pensar en una irresponsabilidad inherente a él. Ciertamente, ésta no se refiere al apoyo de un movimiento político que condujo al abuso y la muerte, sino al hecho de que el pensar político de los Cuadernos Negros pretende desplegarse con la seguridad de un saber fundado, mostrándose, a su vez, como una instancia aclaradora del destino de Occidente, mientras que él mismo no se hace cargo de sí. Se trata de un pensar que tiene por el más alto valor la autoapropiación, pero es ciego a su propio vacío fundamental: a su íntima desapropiación.

En vistas a lo anterior es que, a nuestro juicio, la negación del ahora, avalada por un mero deseo sin asidero concreto alguno, no lleva sino a entender que el pensar político que se abre espacio en los Cuadernos Negros se halla lejano a toda concreción

83 A nuestro juicio, es decisivo el comentario de De Lara: "En general, no obstante, acaba [el discurso filosófico de Heidegger] tendiendo a la construcción, intenta encontrar algo supramundano que dé cuenta última de lo mundano sin serlo ello mismo (por lo que manifiesta una tendencia metafísica y dualista) y pretende además que esa instancia tenga algún poder normativo sobre el mundo en general; sin que por lo demás se preocupe por el mundo concreto, si no es a través de sus propios esquemas de pensamiento, que lo alejan precisamente de dicho mundo" (De Lara, F. «El gesto político de las filosofías de Heidegger. Contribución a un debate actual». Revista Veritas, 31, 2014, p. 84). En el mismo sentido, García de la Huerta señala: "Habría en consecuencia, una doble operación entorno a la política: vaciada inicialmente de verdad, es investida luego de una verdad superlativa, que no es suya, sin embargo, que se la presta el espíritu, y que hace posible el tránsito desde la filosofía a la historia y la política" (García de la Huerta, M., «Relectura 'política' de la cuestión de la técnica». La técnica en Heidegger, 2, Santiago: Universidad Diego Portales, 2007, p. 412).

84 Patočka, J. «Kommentar zum 'Spiegel'-Interview mit Heidegger. Mit einer Diskussion». Ausgewählte Schriften: phänomenologischen Schriften II: Die Bewegung der menschlichen Existenz. Stuttgart: Klett-Cotta, 1991, p. $587 \mathrm{~s}$.

85 Cfr. Bourdieu, P. The political Ontology of Martin Heidegger. California: Standford University Press, 1991. Bourdieu entiende el Nacionalsocialismo heideggeriano inserto en el contexto del Zeitgeist de la Alemania posterior a la Primera Guerra y sus consecuencias culturales, políticas y económicas. Asimismo, cfr. Rockmore, T. On Heidegger's Nazism and Philosophy, op. cit., p. 34, donde se señala que Heidegger fue uno de los muchos que apoyarían el régimen, tales como Bollnow, Gadamer, Gehlen, Lipps, Ritter, entre otros. 
auténtica del filosofar ${ }^{86}$. Tal pensar abandona las cosas y, en última instancia, con su desprecio al presente, niega la disposición necesaria como para constituirse en un pensar radical. Así, con el abandono de las cosas mismas, y su esencial olvido del presente, ese pensar político heideggeriano que pudo esbozarse en sus anotaciones muestra su íntima labilidad ${ }^{87}$, y revela el vacío sobre el cual se erige. Pues bien, y para finalizar, no estaría demás advertir que aquel pensamiento que se ejerció sobre tal labilidad es el que hoy en día, con la publicación de los Cuadernos Negros, despierta y seguirá despertando aún más reproches. Esto no es sino la consecuencia natural del ejercicio de un pensar que pretende iluminar la contingencia, pero que, habiéndola descuidado, queda irremediablemente expuesto a la exigencia permanente de nuevas explicaciones, de nuevas objeciones y de nuevas defensas.

\section{Referencias bibliográficas}

Adrian, J. «Heidegger's Black Notebooks and the Question of Anti-Semitism». Gatherings: The Heidegger Circle Annual, 5, 2015, 21-49.

Aubenque, P. «Otra vez Heidegger y el Nazismo». Revista de Filosofia, I, 1987-88, 157-169. Aurenque, D. «Heidegger y el "enredo" de la filosofía con la política: sobre su origen romántico-platónico». Revista de Filosofía, 66, 2010, 195-213.

Bourdieu, P. The political Ontology of Martin Heidegger. California: Standford University Press, 1991.

Collins, J. Heidegger y los nazis. Barcelona: Ed. Gedisa, 2004.

De Lara, F. «El gesto político de las filosofías de Heidegger. Contribución a un debate actual». Revista Veritas, 31, 2014, 73-86.

Derrida, J. «Del Espíritu». Tres textos sobre Heidegger. Abensour, Levinas, Derrida. Santiago de Chile: Ed. Metales Pesados, 2006.

Farías, V. «El ser y el crimen: los Cuadernos Negros de Martin Heidegger y la espiritualización de la inhumanidad». Stoa, 5, 10, 2014, 105-113.

Fink, E. Welt und Weltlichkeit. Würzburg: Königshausen\& Neumann, 1990.

García de la Huerta, M., «Relectura 'política' de la cuestión de la técnica». La técnica en Heidegger, 2, Santiago: Universidad Diego Portales, 2007.

86 A nuestro parecer, y tomando en cuenta las discusiones del presente trabajo, Romano tiene razón al señalar: "Cuando el antisemitismo, que no es más que una expresión de odio fundado sobre fantasmas, el testimonio más acabado de la ausencia de pensamiento, es integrado al discurso filosófico, no tenemos en absoluto una filosofía antisemita, sino el derrumbe completo de toda posibilidad de la filosofía” (cfr. Romano, C. «L'idee d'antisémitisme philosophique est un non-sens». Critique: Heidegger: la boîte noire des Cahiers, 811, 2015, p. 1013).

87 Nos parece sugerente caracterizar esta "labilidad" como una "banalidad", en directa relación al modo como lo entendiera Hannah Arendt (cfr. Knowles, A. «Heidegger's mask: silence, politics and the Banality on Evil in the Black Notebooks». Gatherings: The Heidegger Circle Annual, 5, 2015, 93-117. p. 96). Y es que el antisemitismo de Heidegger no parece ser sino el que se difundía en la Alemania de la época y que éste habría recepcionado mecánica, pero, a su vez, malignamente. Dicha malignidad se advierte, de hecho, cuando tal "estereotipo" (cfr. Kellerer, S. «La guerra invisible de Martin Heidegger». Stoa, 5, 10, 2014, p. 116 s.) opera en la propia crítica a Husserl. El Heidegger "banal” lleva lo que antes era una posición filosófica estricta a una discusión de razas, en la cual Husserl se vincula a la tendencia racional vacía y calculadora del judío, ajena a las preguntas de alta resolución epocal, como la pregunta por el ser (cfr. Heidegger, M. Schwarze Hefte: Überlegungen XII-XV (1939-1941), op. cit., p. 46 s.) Lo mismo podría decirse de la esperanza en el destino político que discutimos en este escrito: otro elemento presente en los Cuadernos Negros, adquirido sin más de la propaganda política de la época. Así, la alusión a la "banalidad" subraya la peligrosa relación de Heidegger con el Nacionalsocialismo, en términos de una adhesión "mecánica”, erigida en la labilidad del vacío. 
Heidegger, M. Rede und andere Zeugnisse eines Lebensweges. Frankfurt a. M: Vittorio Klostermann, 2000.

Heidegger, M. Schwarze Hefte: Überlegungen II-VI (1931-1938). Frankfurt a. M: Vittorio Klostermann, 2014.

Heidegger, M. Schwarze Hefte: Überlegungen VII-XI (1938/39). Frankfurt a. M: Vittorio Klostermann, 2014.

Heidegger, M. Schwarze Hefte: Überlegungen XII-XV (1939-1941). Frankfurt a. M: Vittorio Klostermann, 2014.

Heidegger, M. Sein und Zeit. Tübingen: Max Niemayer, 2001.

Jaspers, K. Notizen zu Heidegger. Zürich: Serie Piper, 1989.

Marcuse, H. «Herbert Marcuse and Martin Heidegger: An Exchange of letters». New German Critique, 53, 1991, 28-32.

Marcuse, H. «Postcript: My disillusionment with Heidegger». Heideggerian Marxism, London: University of Nebraska Press, 2005, 176.

Kellerer, S. «La guerra invisible de Martin Heidegger». Stoa, 5, 10, 2014, 115-118.

Knowles, A. «Heidegger's mask: silence, politics and the Banality on Evil in the Black Notebooks». Gatherings: The Heidegger Circle Annual, 5, 2015, 93-117.

Patočka, J. «Kommentar zum 'Spiegel'-Interview mit Heidegger. Mit einer Diskussion» Ausgewählte Schriften: phänomenologischen Schriften II: Die Bewegung der menschlichen Existenz. Stuttgart: Klett-Cotta, 1991, 577-612.

Rocha de la Torre, A. «Heidegger: ¿introducción del nacionalsocialismo en la filosofía? Una reflexión en contravía». Franciscanum: Revista de las ciencias del Espíritu. 162, LVI, 2014, 19-49.

Rockmore, T. On Heidegger's Nazism and Philosophy. Oxford: University of California Press, 1992.

Romano, C. «L' idee d'antisémitisme philosophique est un non-sens». Critique: Heidegger: la boîte noire des Cahiers, 811, 2015, 1008-1018.

Sluga, H. Heidegger's Crisis: Philosophy and Politics in Nazi Germany. Cambridge: Harvard University Press, 1995.

Steinbock, A. «Machination, and the Jewish Question: the problem of the gift». Gatherings: The Heidegger Circle Annual, 5, 2015, 50-76.

Steiner, G.: Heidegger. México D. F.: FCE, 2005.

Stevenson, D. 1914-1918: Historia de la Primera Guerra Mundial. Buenos Aires: Debate, 2014.

Trawny, P. Heidegger y el mito de la conspiración mundial de los judíos, Barcelona: Herder, 2015.

Wolin, R. «Introduction to Herbert Marcuse and Martin Heidegger: An Exchange of Letters». New German Critique, 53, 1991, 19-27 